\title{
RANCANG BANGUN DAN UJI PERFORMANSI TURBIN AIR JENIS KAPLAN SKALA MIKROHIDRO
}

\author{
Kusnadi ${ }^{1}$, Agus Mulyono², Gunawan Pakki ${ }^{3}$, Gunarko ${ }^{4}$ \\ Politeknik Angkatan darat \\ Kesatrian Pusdik Arhanud Pussenarh, Kodiklat TNI AD, Desa Pendem Kecamatan Junrejo, \\ Kota Batu, Malang, Jawa Timur \\ Email:kusnadi123@yahoo.com¹, agusmulyono123@yahoo.com², \\ gunawanpakki123@yahoo.com ${ }^{3}$,gunarko123@yahoo.com ${ }^{4}$
}

\begin{abstract}
Abstrak
Air merupakan salah satu sumber energi terbarukan yang dapat dijadikan sebagai sumber energi bagi Pembangkit Listrik Tenaga Mikrohidro (PLTMH). Kota Batu, memiliki sumber energi air yang dapat dijadikan sebagai sumber energi bagi perancangan turbin air untuk prototype PLTMH. Penelitian ini bertujuan untuk mengetahui besarnya daya yang dapat dibangkitkan oleh turbin. Metode yang digunakan dalam penelitian ini adalah metode perencanaan, metode perancangan, metode pengujian, dan metode analisa hasil. Perancangan Turbin Kaplan mengacu pada hasil observasi awal yang menunjukkan bahwa tinggi jatuhnya air (head) 1,6 meter dan kapasitas aliran air (debit) $0,0512 \mathrm{~m}^{3} / \mathrm{s}$. Daya air yang tersedia di kolam sebesar 805, 047 Watt. Hasil perancangan Turbin Kaplan menghasilkan putaran spesifik turbin sebesar 249,372 rpm dengan diameter luar roda turbin (runner blades) 10,70 cm dan diameter dalam roda turbin (boss) 3,56 cm serta tinggi sudu pengarah turbin (guide vanes) 3 $\mathrm{cm}$. Daya indikasi yang dihasilkan turbin air (Water Horse Power) sebesar 351,590 Watt dengan momen puntir sebesar 6,711 Nm dan daya efektif turbin air atau Brake Horse Power (BHP) sebesar 280,964 Watt serta efisiensi turbin sebesar $79 \%$.
\end{abstract}

Kata kunci: Head, debit air, Turbin Kaplan.

\section{PENDAHULUAN}

Energi air dapat dimanfaatkan sebagai pembangkit listrik dengan memanfaatkan tenaga potensial yang tersedia (potensi air terjun dan kecepatan aliran) [1]. Kebutuhan energi dewasa ini semakin meningkat seiring dengan bertambahnya pertumbuhan jumlah penduduk. Namun, pertumbuhan jumlah penduduk dunia tidak disertai dengan ketersediaan pemenuhan energi yang memadai. Hal ini pada akhirnya menyebabkan terjadinya kelangkaan sumber energi. Salah satu upaya untuk mengatasi kelangkaan energi adalah mencari sumber-sumber energi yang baru dan terbarukan yang dapat menggantikan sumber energi minyak bumi yang keberadaannya semakin langka. Selain energi yang berasal dari minyak bumi, kelangkaan juga terjadi pada pemenuhan energi listrik dunia.

Sumber energi yang dapat menghasilkan energi listrik antara lain minyak bumi, batu bara, tenaga nuklir dan air. Minyak bumi dan batu bara keberadaannya sekarang semakin langka dikarenakan sumber energi ini tidak dapat diperbarui. Energi nuklir sebagai pembangkit listrik juga sangat berbahaya bila dikembangkan di Indonesia dikarenakan radiasinya dapat membahayakan penduduk. Salah satu sumber energi penghasil energi listrik yang masih banyak tersedia di Indonesia dan ramah lingkungan adalah sumber energi air. Negara Indonesia sangat berpotensi untuk membangun pembangkit listrik yang menggunakan sumber energi air dikarenakan di wilayah Negara Indonesia 
masih banyak mempunyai sumber daya alam air yang sangat melimpah.

Instalasi yang dapat digunakan untuk memanfaatkan sumber daya air adalah Pembangkit Listrik Tenaga Mikrohidro (PLTMH). PLTMH merupakan pembangkit listrik skala kecil yang memanfaatkan energi air sebagai tenaga penggeraknya. Energi air yang dapat dimanfaatkan sebagai sumber energi berasal dari sungai, air terjun, atau saluran irigasi.

Salah satu sumber air yang dapat dimanfaatkan sebagai sumber energi bagi PLTMH adalah kolam yang berada di lingkungan Lemjiantek. Kolam tersebut difungsikan sebagai bendungan penampung air. Berdasarkan observasi awal yang dilakukan oleh peneliti terhadap kolam air yang terdapat di Lemjiantek, maka turbin air yang sesuai untuk digunakan sebagai penggerak adalah Turbin Kaplan [2].

Penelitian ini bertujuan untuk mengetahui daya yang dapat dibangkitkan turbin dengan sumber daya alam yang tersedia di Politeknik Angkatan Darat sebagai prototype PLTMH dengan menggunakan turbin air jenis Kaplan.

\section{TINJAUAN PUSTAKA}

\section{Pembangkit Listrik Tenaga Mikrohidro}

Pembangkitan tenaga air dengan

skala kecil atau pembangkitan tenaga mikrohidro merupakan suatu bentuk perubahan tenaga dari tenaga air dengan tinggi jatuh air (head) dan kapasitas aliran air (debit) tertentu, diubah dengan menggunakan sistem tertentu menjadi tenaga listrik [3].

Lokasi untuk PLTMH harus di observasi terlebih dahulu apakah terdapat potensi tenaga air yang dapat dimanfaatkan. Potensi tenaga air yang dimaksud yaitu besarnya sumber tenaga air yang memiliki head dan debit yang tersedia. Kedua faktor inilah yang dapat mempengaruhi besarnya daya listrik yang dihasilkan oleh generator/alternator PLTMH.

\section{Turbin Air}

Turbin secara umum dapat diartikan sebagai mesin penggerak mula dimana energi fluida kerja yang digunakan langsung memutar roda turbin, fluida kerjanya berupa air, uap dan gas. Dengan demikian turbin air dapat diartikan sebagai suatu mesin penggerak mula yang fluida kerjanya adalah air.

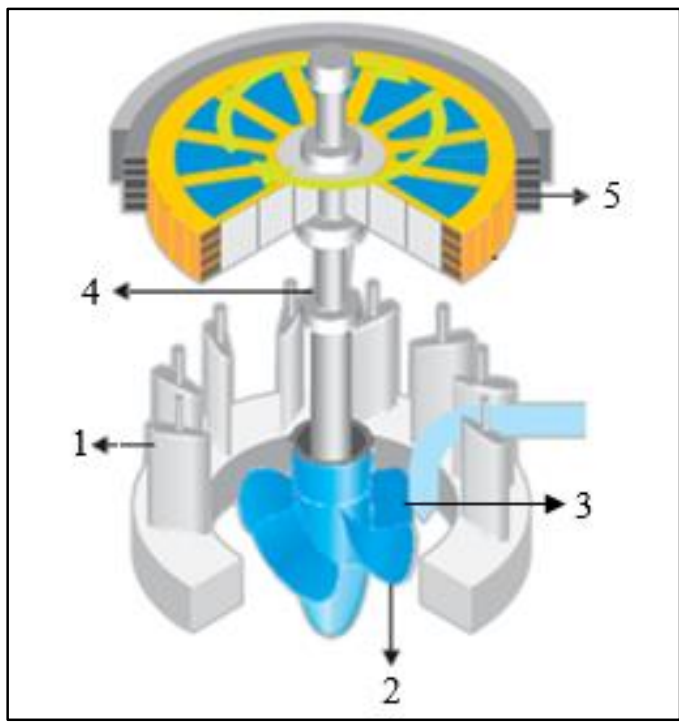

Gambar 1. Turbin air poros vertikal [8]

Keterangan gambar:

1. Sudu pengarah turbin (guide vanes)

2. Sudu gerak turbin (blades)

3. Roda turbin (runner blades)

4. Poros turbin

5. Generator/Altenator listrik

Secara umum prinsip kerja dari turbin air adalah aliran air di dalam pipa pesat yang mempunyai energi potensial dan energi kinetik diarahkan ke roda turbin melalui sudu pengarah, kemudian energi yang terdapat di dalam air ini pada roda turbin diubah bentuknya menjadi energi mekanik berupa putaran poros roda turbin. Putaran poros roda turbin inilah yang dimanfaatkan untuk menggerakkan generator/altenator pembangkit listrik [4].

\section{Pemilihan Jenis Turbin Air}

Pada dasarnya pemilihan jenis turbin untuk PLTMH terlebih dahulu harus diketahui besarnya head dan besarnya debit. Setelah mengetahui berapa besarnya head dan debit air yang tersedia, maka 
pemilihan jenis turbin air yang akan digunakan dapat ditentukan. Pemilihan jenis turbin dapat pula ditentukan dengan menggunakan tabel kriteria pemilihan jenis turbin air berdasarkan head yang tersedia (Tabel 1) dan grafik Turbine Application Chart (Gambar 2).

Tabel 1. Kriteria Pemilihan Jenis Turbin Air Berdasarkan Head [8]

\begin{tabular}{|l|c|}
\hline Jenis Turbin & Variasi Head $(\mathbf{m})$ \\
\hline $\begin{array}{l}\text { Kaplan atau } \\
\text { Propeller }\end{array}$ & $1<\mathrm{H}<20$ \\
\hline Francis & $10<\mathrm{H}<350$ \\
\hline Pelton & $50<\mathrm{H}<1000$ \\
\hline Crossflow & $6<\mathrm{H}<100$ \\
\hline Turgo & $50<\mathrm{H}<250$ \\
\hline
\end{tabular}

Pada grafik Turbine Application Chart digambarkan secara jelas kriteria berbagai macam jenis turbin air dengan head dan debit air tertentu. Turbin air dapat diklasifikasikan berdasarkan beberapa cara, namun yang paling utama adalah klasifikasi turbin air berdasarkan prinsip kerjanya. Berdasarkan prinsip kerjanya turbin air dibagi menjadi dua bagian yaitu Turbin Impuls dan Turbin Reaksi [5].

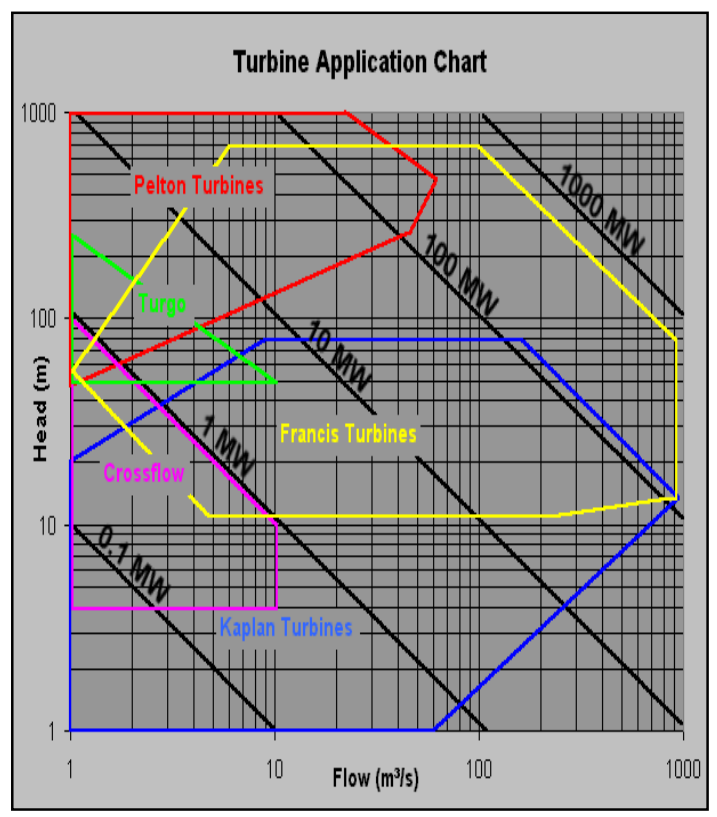

Gambar 2. Gambar Grafik Pemilihan Jenis Turbin Air [8]

\section{Turbin Air Jenis Kaplan.}

Turbin air Kaplan merupakan salah satu jenis dari turbin reaksi. Turbin Kaplan tersusun dari propeller/sudu-sudu roda turbin seperti baling-baling kapal. Roda turbin Kaplan berfungsi untuk mendapatkan gaya putar/tangensial pada poros turbin yang dapat menghasilkan Torsi.

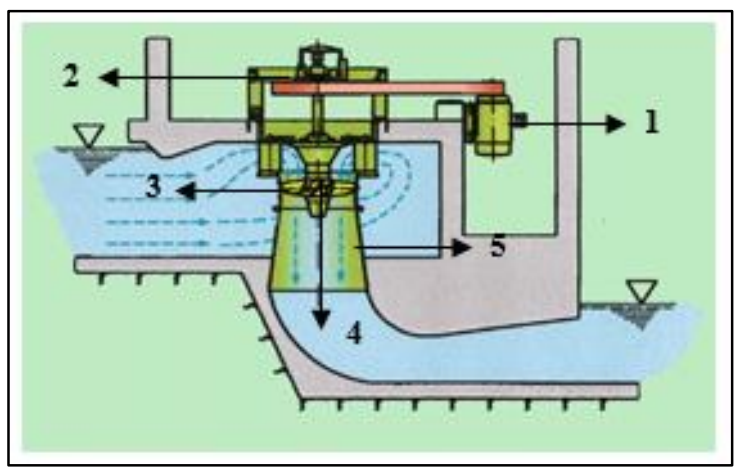

Gambar 3. Turbin Air Jenis Kaplan [8]

Keterangan:

1. Generator/alternator listrik

2. Sistem transmisi

3. Sudu gerak (blades)

4. Roda turbin (runner blades)

5. Saluran pelepasan (draf tube)

\section{METODOLOGI PENELITIAN.}

\section{Perancangan Alat}

Sebelum

melaksanakan perancangan turbin air sebagai PLTMH di Lemjiantek, maka terlebih dahulu harus ditentukan beberapa data untuk perancangan alat. Adapun data-data yang ditentukan adalah sebagai berikut:

1. Bahan logam yang direncanakan untuk turbin air jenis Kaplan adalah Stainsless Steel 304 dengan tebal plat 1 mm,

2. Penghitungan head dan debit yang ada.

\section{Komponen Pendukung PLTMH}

Komponen pendukung yang dibutuhkan dalam perancangan turbin sebagai penggerak PLTMH adalah sebagai berikut:

1. Kolam penampungan air sebagai sumber energi. Kolam penampungan air yang digunakan adalah kolam yang terdapat di Lemjiantek yang mendapat aliran air dari saluran irigasi Sungai Brantas, 
2. Pipa pesat (penstock). Air dari kolam penampungan air dialirkan menuju bak penampung air sebagai rumah turbin melalui penstock. Pipa pesat yang akan dipasang direncanakan 2 buah karena untuk menyuplai bak air dibutuhkan jumlah debit yang cukup banyak sehingga seluruh bagian bawah turbin dapat tenggelam,

3. Bak penampung air. Bak penampung air berfungsi untuk menenggelamkan turbin air. Bak penampung air ini digunakan sebagai pengganti rumah turbin karena air yang terdapat di dalam bak diarahkan oleh sudu pengarah menuju roda turbin yang terdapat di dalam saluran pelepasan. Di dalam saluran pelepasan terjadilah vortek (pusaran air) sehingga dapat memutarkan roda turbin.

\section{Konstruksi Turbin Kaplan.}

Konstruksi Turbin Kaplan yang akan dirancang dan dibuat adalah sebagai berikut (Gambar 4).

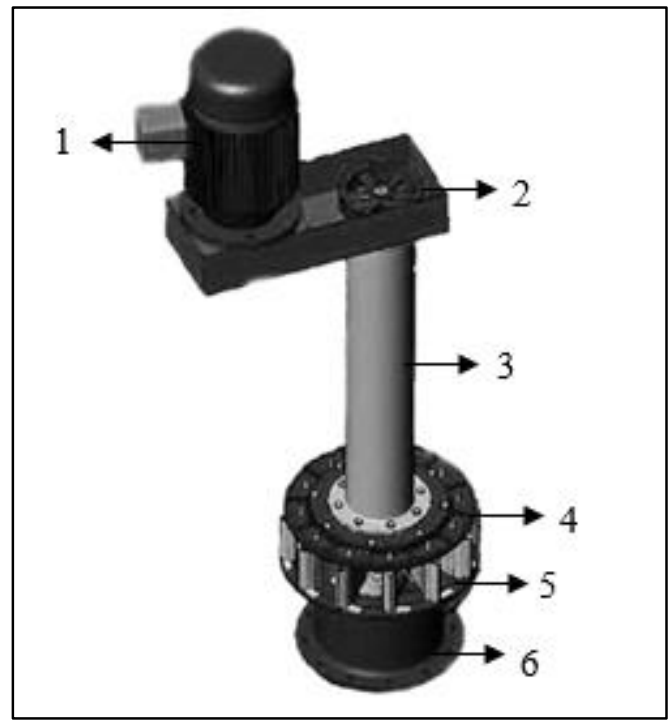

Gambar 4. Desain konstruksi Turbin Kaplan

Keterangan:

1. Generator listrik

2. Puli

3. Poros turbin

4. Sudu pengarah (guide vanes)

5. Roda turbin (runner blades) yang terdapat di dalam draf tube

6. Saluran pelepasan (draf tube)

\section{Diagram Alir}

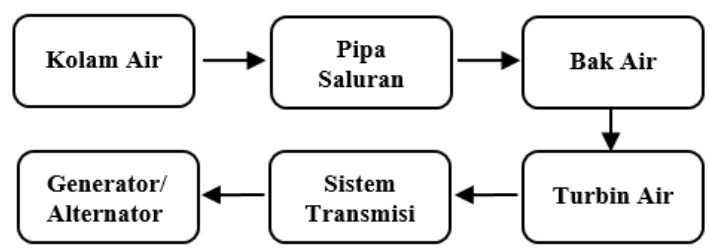

Gambar 5. Diagram alir proses konversi energi air

Berdasarkan diagram alir di atas, maka cara kerja alat adalah sebagai berikut:

1. Air dari kolam penampungan dialirkan menuju ke bak penampung air sebagai rumah turbin melalui pipa penstock. Air yang keluar dari pipa saluran kemudian ditampung dalam bak penampung air sehingga mencapai head 1,6 meter.

2. Air dalam bak penampung yang menenggelamkan bagian bawah turbin diarahkan oleh sudu pengarah menuju ke roda turbin yang terdapat di dalam saluran pelepasan.

3. Air yang masuk ke dalam saluran pelepasan kemudian dihisap oleh saluran sehingga timbul vortek (pusaran air) yang dapat memutarkan roda turbin.

4. Penempatan turbin harus tepat pada saluran pelepasan dan tidak boleh miring ataupun ada kebocoran pada penempatannya. Karena apabila pada saluran pelepasannya terjadi kebocoran akan menyebabkan tekanan air di dalam pipa saluran akan sama dengan tekanan udara luar sehingga poros turbin tidak akan berputar secara maksimal.

\section{HASIL DAN PEMBAHASAN}

Perancangan Turbin Kaplan sebagai penggerak bagi prototype PLTMH didasarkan pada penghitungan awal terhadap sumber daya air yang terdapat di Lemjiantek didapatkan head sebesar 1,6 m dan kapasitas aliran air sebesar $0,0224 \mathrm{~m}^{3} / \mathrm{s}$. Komponen-komponen yang terdapat pada perancangan Turbin Kaplan dihitung dengan menggunakan persamaan 
Fritz Dietzel didapatkan hasil sebagai berikut:

1. Daya Air

$$
\begin{aligned}
\mathrm{N} & =\rho \cdot g \cdot Q \cdot \mathrm{H}(\mathrm{Watt}) \\
& =1000 \frac{\mathrm{kg}}{\mathrm{m}^{3}} \cdot 9 \cdot 81 \frac{\mathrm{m}}{\mathrm{s}^{2}} \cdot 0,05129 \frac{\mathrm{m}^{3}}{\mathrm{~s}} \cdot 1,6 \mathrm{~m} \\
& =805,047 \mathrm{Watt}
\end{aligned}
$$

2. Kecepatan Spesifik Turbin Kaplan

$$
\begin{aligned}
\mathrm{n}_{\mathrm{S}} & =\frac{\mathrm{n} \cdot \sqrt{\mathrm{N}}}{\mathrm{H}^{5 / 4}}(\mathrm{rpm}) \\
& =\frac{500 \mathrm{rpm} \cdot \sqrt{0,805047}}{1,6 \mathrm{~m}^{5 / 4}} \\
& =\frac{448,622}{1,799} \\
& =249,372 \mathrm{rpm}
\end{aligned}
$$

3. Diameter Luar Roda Turbin Kaplan

$$
\begin{aligned}
\text { De } & =\frac{60 . \mathrm{u}}{\pi \cdot \mathrm{n}}(\text { Watt }) \\
& =\frac{60.2,8 \frac{\mathrm{m}}{\mathrm{s}}}{3,14.500 \mathrm{rpm}} \\
& =\frac{168 \mathrm{~m}}{1570} \\
& =0,1070 \mathrm{~m}
\end{aligned}
$$

4. Diameter Dalam Roda Turbin Kaplan

$$
\begin{aligned}
\frac{\mathrm{d}}{\mathrm{D}} & =\frac{1}{3} \\
\mathrm{~d} & =\frac{1}{3} \mathrm{D}(\mathrm{m}) \\
& =\frac{0,1070 \mathrm{~m}}{3} \\
& =0,03566 \mathrm{~m}
\end{aligned}
$$

5. Tinggi Sudu Pengarah Turbin Kaplan

$$
\begin{aligned}
\mathrm{b}_{\mathrm{o}} & =\frac{\mathrm{Q}}{\mathrm{D} \cdot \pi \cdot \mathrm{c} \cdot \tau}(\mathrm{m}) \\
& =\frac{0,05129 \frac{\mathrm{m}^{3}}{\mathrm{~s}}}{0,1070 \mathrm{~m} \cdot 3,14 \cdot 5,6 \frac{\mathrm{m}}{\mathrm{s}} \cdot 0,9} \\
& =\frac{0,05129 \mathrm{~m}}{1,6933} \\
& =0,03028 \mathrm{~m}
\end{aligned}
$$

6. Daya Indikasi Turbin Kaplan

$$
\begin{aligned}
\mathrm{Ni} & =\rho \cdot g \cdot \mathrm{Q} \cdot \mathrm{H} \cdot \eta_{\mathrm{t}}(\text { Watt }) \\
& =1000 \frac{\mathrm{kg}}{\mathrm{m}^{3}} \cdot 9,81 \frac{\mathrm{m}}{\mathrm{s}^{2}} \cdot 0,02243 \frac{\mathrm{m}^{3}}{\mathrm{~s}} \cdot 1,6 \mathrm{~m} \\
& =351,590 \text { Watt }
\end{aligned}
$$

7. Torsi Turbin Kaplan

$$
\begin{aligned}
\mathrm{T} & =\text { Q.p.c.r }(\mathrm{Nm}) \\
& =0,0224 \frac{\mathrm{m}^{3}}{\mathrm{~s}} \cdot 1000 \frac{\mathrm{kg}}{\mathrm{m}^{3}} \cdot 5,6 \frac{\mathrm{m}}{\mathrm{s}} \cdot 0,0535 \mathrm{~m} \\
& =6,711 \mathrm{Nm}
\end{aligned}
$$

8. Daya Efektif Turbin Kaplan

$$
\begin{aligned}
\mathrm{Ne} & =\mathrm{T} . \omega(\text { Watt }) \\
& =6,711 \mathrm{Nm} \cdot 2 \cdot 3,14.400 \mathrm{rpm} / 60 \\
& =280,964 \text { Watt }
\end{aligned}
$$

9. Efisiensi Turbin Kaplan

$$
\begin{aligned}
\eta & =\frac{\mathrm{Ne}}{\mathrm{Ni}} \times 100 \% \\
& =\frac{280,964}{351,590} \\
& =0,79 \times 100 \% \\
& =79 \%
\end{aligned}
$$

Tabel 2. Data Hasil Pengujian Alat

\begin{tabular}{|c|c|c|c|c|c|}
\hline $\begin{array}{c}\text { Head } \\
(\mathrm{m})\end{array}$ & $\begin{array}{c}\text { Debit } \\
\left(\mathrm{m}^{3} / \mathrm{s}\right)\end{array}$ & $\begin{array}{c}\text { Putaran } \\
\text { Poros } \\
(\mathrm{rpm})\end{array}$ & $\begin{array}{c}\text { Daya } \\
\text { Indikasi } \\
(\text { Watt })\end{array}$ & $\begin{array}{c}\text { (Daya } \\
\text { Efektif } \\
(\text { Watt) }\end{array}$ & $\begin{array}{c}\text { Efisi } \\
\text { ensi } \\
(\%)\end{array}$ \\
\hline 1,6 & 0,02237 & 2000 & 351,590 & 280,967 & 80 \\
\hline 1,5 & 0.02031 & 1800 & 298,714 & 210,725 & 71 \\
\hline 1,4 & 0.01831 & 1600 & 251,332 & 158,044 & 63 \\
\hline 1,3 & 0.01638 & 1300 & 207,873 & 122,923 & 59 \\
\hline 1,2 & 0.01453 & 1000 & 171,047 & 70,241 & 41 \\
\hline
\end{tabular}

Grafik Hubungan Debit Terhadap Head

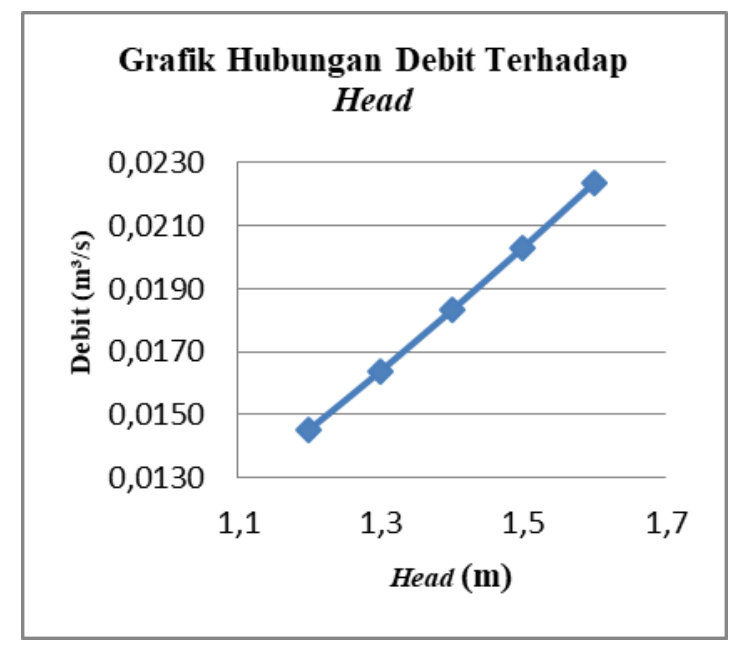

Gambar 5. Grafik hubungan antara debit terhadap head

Dari Gambar 5 grafik hubungan antara debit terhadap head, maka dapat dilihat bahwa head semakin tinggi maka debit yang dihasilkan juga semakin besar. Hal ini disebabkan karena besarnya debit air dipengaruhi oleh head yang tersedia. 
Grafik Hubungan Putaran Turbin Terhadap Head

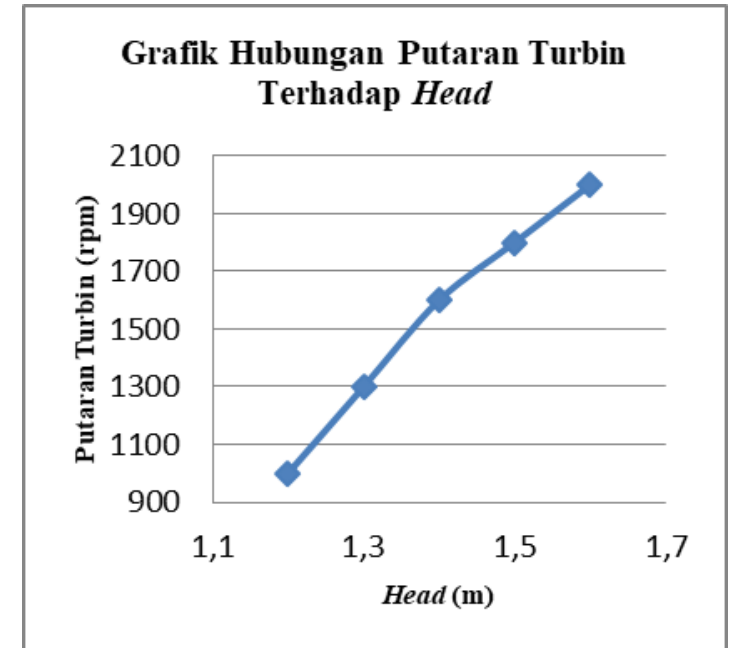

Gambar 6. Grafik hubungan antara putaran turbin terhadap head

Dari Gambar 6 grafik hubungan antara putaran turbin terhadap head, dapat dilihat bahwa head semakin tinggi maka putaran turbin yang dihasilkan juga semakin besar. Hal ini disebabkan karena besarnya putaran turbin dipengaruhi oleh head yang tersedia.

\section{Grafik Hubungan BHP Terhadap Head}

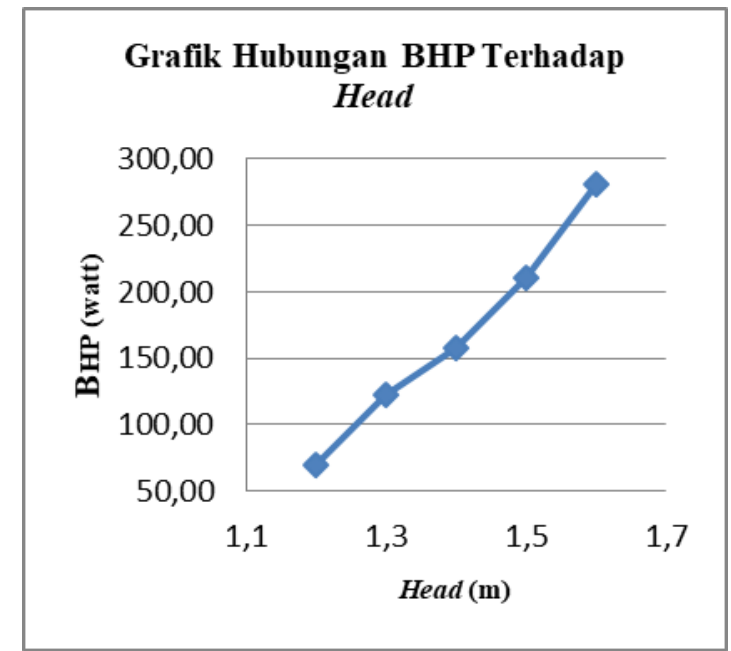

Gambar 7. Grafik hubungan antara BHP

Dari Gambar 7 grafik hubungan antara BHP terhadap head, maka dapat dilihat bahwa head semakin tinggi maka BHP turbin yang dihasilkan juga semakin besar. Hal ini disebabkan karena besarnya BHP dipengaruhi oleh besarnya head yang tersedia.

\section{Grafik Hubungan Efisiensi Terhadap Head}

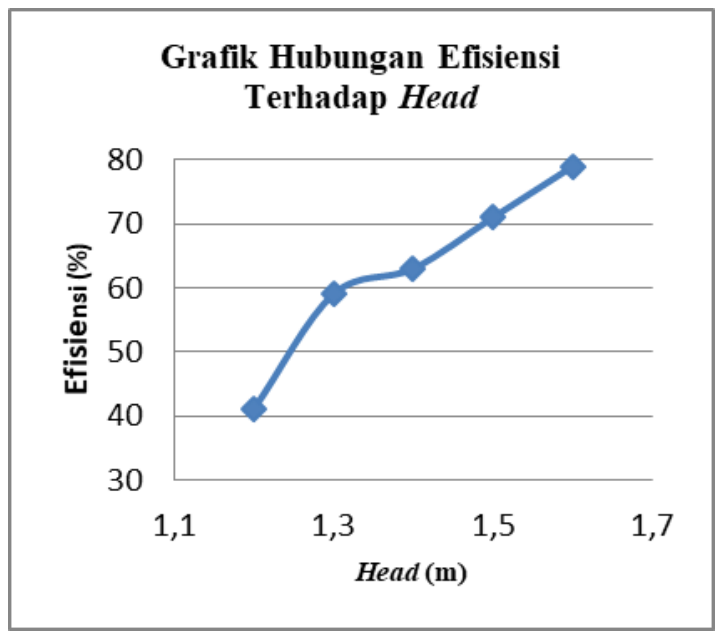

Gambar 8. Grafik hubungan antara efisiensi terhadap head

Dari Gambar 8 grafik hubungan antara Efisiensi terhadap head, maka dapat dilihat bahwa head sebesar 1,2 m memiliki efisiensi sebesar $41 \%$. Semakin naik head pada bak penampung air maka efisiensi yang dihasilkan semakin tinggi. Hal ini disebabkan karena besarnya efisiensi dipengaruhi oleh besarnya BHP yang dihasilkan turbin.

\section{KESIPULAN DAN SARAN}

\section{Kesimpulan}

Berdasarkan penghitungan head dan kapasitas aliran air pada kolam ikan di Lemjiantek, didapatkan head sebesar 1,6 m dan debit $0,0224 \mathrm{~m}^{3} / \mathrm{s}$ maka turbin air yang tepat sebagai penggerak pada prototype PLTMH di Lemjiantek adalah Turbin Kaplan. Daya air yang tersedia di kolam sebesar 805,047 Watt.

Hasil perancangan Turbin Kaplan menghasilkan putaran spesifik turbin sebesar 249,372 rpm dengan diameter luar roda turbin $10,70 \mathrm{~cm}$ dan diameter dalam roda turbin (boss) $3,56 \mathrm{~cm}$ serta tinggi sudu pengarah $3 \mathrm{~cm}$.

Daya indikasi yang dihasilkan turbin air (Water Horse Power) sebesar 351,590 Watt dengan momen puntir sebesar 6,711 $\mathrm{Nm}$ dan daya efektif turbin air (BHP) sebesar 280,964 Watt serta efisiensi turbin sebesar $79 \%$. 
Saran

Penelitian ini masih perlu disempurnakan lagi karena instalasi pipa saluran air yang digunakan sekarang kurang untuk mensuplai air ke dalam bak, sehingga perlu ditambah lagi pipa salurannya serta disempurnakan lagi instalasinya.

Generator yang digunakan sekarang ini adalah alternator mobil dengan arus DC sehingga perlu disempurnakan lagi menggunakan generator dengan arus AC.

Pada penelitian selanjutnya disarankan untuk pengujian Turbin Kaplan ini dilaksanakan di tempat yang memiliki head dan debit yang selalu ada (konstan) sehingga dapat dianalisa dan dilihat seberapa besar efisiensi yang dapat dihasilkan oleh turbin.

\section{REFERENSI}

[1]. Irawan, D. (2014). PROTOTYPE TURBIN PELTON SEBAGAI ENERGI

ALTERNATIF

MIKROHIDRO DI

LAMPUNG. Turbo: Jurnal

Program Studi Teknik Mesin, 3(1).

[2]. Arismunandar, Artono dan S.

Kuwahara, Teknik

Tenaga Listrik. Jakarta: PT.

Pradnya Paramita.

[3]. Arismunandar, Wiranto, (1982), "Penggerak Mula Turbin". Bandung: ITB.

[4]. Banga T.R. dan S.C. Sharma, (1984), Hydraulic Machines. Delhi: Khanna Publisher

[5]. Dietzel Fritz, (1999), Turbin, Pompa dan Kompresor. Jakarta: Erlangga.

[6]. ESHA, (2004), "Guide on How to Develop a Small Hydropower Plant". Belgia: ESHA

[7]. Kjolle, Arne, (2001), "Mechanical Equipment", Norwegia:
Norwegian University of Science and Technology.

[8]. Layman's Guidebook's. (1998), "on how to develop a small hydro site", Belgia: ESHA

[9]. M.M. Dandenkar dan K.N. Sharma, (1991), "Teknik Pembangkit Listrik Tenaga" Air. Jakarta: Universitas Indonesia

[10]. Paryatmo Wibowo. 2007. Turbin Air, Yogyakarta: Graha Ilmu 